STAN BERNSTEIN is an advanced graduate student in the Doctoral Program in Social Psychology, The University of Michigan. His major theoretical interests are in the areas of commitment, resocialization, and non-verbal communication. He is currently doing field research on commitment and intensive resocialization.

\title{
GETTING IT DONE: Notes on Student Fritters
}

\author{
STAN BER NSTEIN
}

EOCIAL ROLES VARY in the degree to which their constituent tasks are "closed" or "open" in character. At one extreme are roles such as assembly-line worker, where precise definitions communicate when the task starts, one's progress in it, and when it ends. At the other extreme are roles such as student, where the tasks are highly open or never-ending. The role of student, in particular, involves learning to think and learning the "facts" of various fields. The infinite expandibility of these tasks places no practically determined restrictions on the amount of time occupants can dedicate to the role. Like politicians, housewives, and other entrepreneurs, students' work is never done. Indeed, students are counselled that people only stop learning when they die. Death is not, students lament, in sight, but learning demands are.

This paper seeks to explore how people cope with roles that are open or never-ending in their demands. In particular, it

AUTHOR'S NOTE: The author acknowledges the invaluable assistance of $\mathrm{Mr}$. Jeff Hart (Boston College) in the development of the idea of fritter. Special thanks are due Ms. Susan Wilcox for assistance. 
focuses upon how students justify not working under the ever-present pressure to work. Frequently, when there is work to be done, students fritter away time. An analysis of strategies students adopt in accounting for their time not working will be presented. The objective truth or falsity of the strategies is irrelevant to the purpose of this analysis. What is important is their use in coping with open-ended situations.

\section{NEUTRALIZATION, ACCOUNTS, ANO FRITTERS}

The present effort both follows and departs from prior research. Matza (1964) discusses how an individual in a subculture of delinquents neutralizes his guilt over performing delinquent acts. Relevant here, Matza notes that the delinquent's relation to the norms he violates includes strong elements of normative acceptance. It is not sheer rejection of legal norms but, for most, ambivalence or acceptance with definitions of extenuating circumstances. Students' attitudes toward normatively expected study are also frequently complex and ambivalent. Matza notes that delinquents only occasionally commit delinquent acts. Intermittent violation is also a characteristic of most students' work avoidance.

An important element in Matza's discussion is the fact that neutralization techniques are common in the subculture of delinquency as a way of freeing the individual from moral constraint in violating legal norms. The legal system is the one which labels the acts deviant. The relationship of the definitions of justified action of the delinquent groups to the social control agents' definitions is studied. In individual role management, however, the individual is his own social control agent. It is not clear whether the neutralizations in Matza's discussion are to be considered as justified accounts to others (especially members of one's own group), or primarily as accounts to self.

A more general presentation of accounts can be found in the excellent treatments by Scott and Lyman (1970, 1968). In introducing their discussion, they present the study of accounts 
as necessary for an understanding of the maintaining of social order after failure to meet social expectations. How does the individual explain his act to others when he has not met their expectations?

(1) How does he excuse his wrong action (escape responsibility) or,

(2) how does he justify his behavior (neutralize the pejorative portrayal of the consequences)?

Accounts repair the breaks in satisfying the expectations of others. Scott and Lyman's presentation is complex. Group differences in acceptable accounts, the style of accounts, audience selection for accounts, and many other questions are sensitively handled. The relation of accounts given to others and accounts offered to self in role management is, however, not discussed. Accounts are considered part of a sociology of talk. An account is "a statement made by a social actor to explain unanticipated or untoward behavior-whether the behavior is his own or that of others, and whether the proximate cause for the statement arises from the actor himself or someone else" (Scott and Lyman, 1968: 46). To their discussion, I here add that the recipient of the account may be the actor himself. Further, an explanation may succeed as an account only for the actor.

This analysis treats a student population. It is this population that the author knows best from years of active participation as an undergraduate and graduate student, and, as a teacher of undergraduates in two college settings. The central notion is that of fritter devices or strategies. A fritter is "a justification a student gives to himself for not doing student work in response to felt pressures to work." While the success of a fritter in neutralizing work pressure or guilt is increased by its receiving social support, this consideration is not part of the definition.

The dynamic nature of fritters makes categorizing them difficult. In actual practice, combinations or complex sequences are likely as the student continually reconstitutes his workavoiding as new kinds of justified activity. For ease of presentation, they may be divided into four classes: (1) per- 
son-based; (2) social relations-based; (3) valuative-based; and (4) task-based.

\section{PERSON-BASED FRITTERS}

Person-based fritters involve definitions of biological need and personal history.

\section{Biological Necessity}

Even a student is human. Being human involves, among other things, the satisfaction of biological needs. These practical necessities are just that-necessities. Therefore, they are foolproof justifications for not working. When, for example, nature calls, what is a person to do but respond to his mother's entreaty? Similarly, hunger can serve as a justification for work avoidance. Not only can an argument be made for biological necessity, but the student can also argue that hunger impairs studying ability. This argument need not be limited, of course, by actual hunger. The great business done by vending machines in dormitories and the concentration of all-night eating places in areas of high student residence attest to the utility of this justification. Some popular student foods (pizza in particular) are not eaten alone. Time must be spent gathering other people. And once you have them, you can do more with them than eat.

Cleanliness is yet another excellent justification. Anything next to godliness surely takes precedence over work. Washing and showering can serve another function. An entire battery of work-avoidance tactics can be justified by their necessity in keeping the student awake. These activities include preparing and drinking cups of coffee, cold showers, long walks in cold weather, running a half-mile, standing on one's head for a few minutes, listening to Sousa marches, Chopin preludes, or acid rock, and eating rich food. A variety of drugs are now routinely used to fight fatigue. The effects of these are frequently not restricted to fatigue reduction. Subtle and not very subtle alterations of consciousness are common. Attending to these 
shanges can become more interesting than studying. Should these activities fail, or even should they succeed, another way of andling "fatigue" is the I'll-get-up-very-early-tomorrownorning-when-I'll-be-able-to-work-better fritter. Students have oo keep healthy, too. Many regimens, physical and medical, may se required. At some times, it may be crucial that the student jet "adequate rest."

\section{Rest on Your Laurels}

Focusing on personal history leads to the nostalgia or rest-on-your-laurels fritter. Using this strategy involves employng past accomplishments as justification for present work ivoidance. This can take the form of delaying work, since previous history shows (or can be interpreted to suggest) it well within one's capability and therefore not a matter of pressing zoncern. Or when the present activity proves frustrating to the point of work avoidance, the individual may bolster his esteem by "celebrating" previous successes. A variant on this theme is zspecially handy for avoiding work when a number of different tasks must be done. Upon completion of one of them, the student may use a you-owe-it-to-yourself justification for work avoidance, the avoidance period being defined as self-payment for a job well done.

An owe-it-to-yourself break may also be seen as necessary to let the worker change psychological set or recover from fatigue. More work is more fatiguing than almost any nonwork activity. It is easier to change set to most nonwork acts than to most ther work.

\section{SOCIAL RELATIONS-BASED FRITTERS}

Fritters based upen social relations directly employ other people in the action of avoiding work. The impact of employing other people, however, is not so much in having an audience before which one gives accounts as simply in having an audience. There are three main patterns of social relations fritters. 


\section{Group Discussion}

The group-discussion fritter is also called the commiseration fritter. Commiserating may be done in a large group or in pairs either in person or over the telephone. It involves "getting together" and consoling one another on the unreasonability or irrationality of the assignment. Complaining about the assigned work is an excellent fritter technique. It justifies work avoidance by directly protesting against the work itself. The more intelligent or discriminating the complaints, the clearer it is that the work task is within the student's later capability. Critical ability may be developed in avoiding studying as well as in doing studying. Sometimes discussions of this sort get around to a comparison of actual work done, leading to the socialcomparison fritter.

\section{Social Comparison}

Students sometimes compare their progress with one another. When a student discovers he is ahead of others in his work, he can then feel justified in freeing time for work avoidance. This fritter has two aspects. First, there is the time spent gathering comparisons of others. This may involve personal contact or telephoning. Or the comparison others may not be real others working on the same task. Instead, high relative standing earlier in the course may be extrapolated to the present. Because of information from the past, the student may believe he is at present ahead of others. When this is coupled with the perception that relative position is the criterion of final evaluation, it becomes possible, for example, for "curve-breaking" midterm students to free time from final studies and projects. Second, there is the effect of the comparison. The choice of comparison others is a strategic choice. For a student to feel justified in his current work avoidance, he must compare his work with someone who is less advanced than he. (Choice of other will vary depending on whether the student wishes to take a break from work or gain incentive to continue it.) The two dangers of this technique for the student are: first, he may 
choose someone who is, in fact, more advanced in the work; and, second, he may fritter away the time needed for students to catch up and pass him. This second possibility exists because, in seeking a justification for work avoidance, students frequently stop at discovering they are ahead, do not collect information on the rate of progress of others, and thus easily misestimate the time it takes others to close the gap. This problem is less threatening and the fritter more successful if the time before the deadline is small. One possible result of such a technique is to make distributions of student performance more closely approximate the normal curve than would otherwise be the case.

\section{Group Work}

The decision to study in a group has a number of work-avoidance functions. On the one hand, it immediately makes possible commiseration and social-comparison fritters. Study groups from the same course can, of course, commiserate easily. Students studying together, but for different courses, are able to have even longer commiseration sessions. Each can complain about his course without redundancy and without risk of contradiction or challenge. Social-comparison fritters are also possible both as a group enterprise in relation to a group-defined standard of adequate knowledge for the course and as a sort of distributive justice notion for comparison between courses with groups of students studying for different courses. A group norm of "reasonable work for any course" can then develop independent of the actual demands of the actual courses being studied.

Getting a number of people together functions, on the other hand, to increase enormously the range of alternatives to studying. These activities can be justified using any number of the techniques elsewhere mentioned. Work avoidance maneuvers with group approval are especially difficult to ignore. There is a "risky shift" in the direction of longer fritters, too. This is because. once you have stopped working, it is difficult to know 
when to suggest to your partners that you should get back to work. It may be hard to stop frittering without being impolite or pressuring. Responsibility for directing attention back to work becomes diffused through the group.

\section{VALUATIVE-BASED FRITTERS}

While the above-mentioned fritter techniques are common and successful, they do not have the guilt-binding power of valuative fritters. One way work can be avoided especially, but not exclusively, in the early college years is using time to discuss values. Political, moral, and aesthetic topics are common in these conversations. Finding out who you are, "getting your shit together," and so on is an important task. Mundane work considerations do not look very important measured against this larger activity. Valuative fritters based on already-held values place work and work avoidance within a larger framework of values and choices. It is here that considerations of nonstudent activities enter with greatest effect. Three primary types of valuative fritters may be described and ordered in terms of increasing generality and abstraction.

\section{Higher Good}

In the higher-good work-avoidance strategy, the student ranks being a student as less important to him in his scheme of values than other interests and aspects of his identity. Here friendship, love, cultural values (e.g., charity, service), political interests, physical fitness (the sound-mind-in-a-sound-body fritter), and much else can be justified as more worthy of attention for the moment than the study tasks at hand. These other values, of course, vary in strength and, therefore, in their guilt-free binding power in role management. For this reason, the strength of each of the alternative values is enhanced immeasurably if it can be asserted that the opportunity for acting on that value is soon to be gone. Stated another way, rare events, or at least infrequent events, have a special ability to 
bind time from studying, even if the value of the act would otherwise be questionable in relation to the pressure to study. Makes-Jack-a-dull-boy valuative fritters, involving, say, a movie, will be more potent the last day the picture is playing than the first day of an extended run, concerts involving great and infrequently heard performers are able to appease guilt from role violation, and eclipses of the moon draw crowds of guilt-free students as an audience.

\section{Experience Broadens}

The experience-broadens fritter is less specific in the sense of presenting a less clear-cut value conflict. It has, nonetheless, the attraction of serving as a ready back-up to a post-facto unjustified valuative fritter (say, the movie was lousy, the instruments out of tune, the friend crabby, the eclipse cloud-ridden, or what have you). In such an event, or generally in any event, it can be argued somehow that experience qua experience broadens the person, makes him more complete, or wiser, or what have you. This can bind successfully enormous amounts of time on a scale much larger than the mere work requirements for a specific course. Even career decisions (or decision evasions) can be justified under the experience-broadens rubric. The crucial difference from the higher-good fritter is that any experience will do.

\section{Existential}

The most general of valuative fritters is the existential, or the what-the-hell-sort-of-difference-will-it-make fritter. In this strategy, the decision to work or not work is cast as having no lasting practical or existential effect on the course of one's life (or, sometimes, other's, as in the would-be author's no-one-willbe-reading-novels-in-ten-years-anyway fritter). Scholastic failures of prominently successful individuals may be remembered. Einstein's failure of a high school math course can offer solace to the fritterer. If one's activities are ultimately of no consequence anyway, the immediate consequences of work 
avoidance are not even worthy of consideration. Extreme application of this principle can lead to failure in the student role, in which event one's very studenthood may be justified as an experience-broadens fritter from what one should really be doing.

\section{TASK-BASED FRITTERS}

Fritters discussed to this point are based upon the student's history, biology, social relations, and values. We come finally to the task itself. Task-based fritters focus upon the direct handling of study time and the allocation of work resources. Specifically, there appear to be four main clusters of task-based fritters: time-related; preparation-related; creativity-related; and task-involved.

\section{Time Related Fritters}

\section{THE TIME SYMMETRY FRITTER}

Many students appear to find it easier to start studying on the hour, half-hour, or, at the very least, quarter-hour than at any other minute. This may be due to the ease these times make for scheduling fritters discussed below. These times are more generally important in plans and schedules between individuals. A common social use of time shapes action. (On a larger scale, weekends, holidays, or Mondays assume special status in the week.) It is, further, "easier" to compute total study time and pages per hour if you start at some such prominent time division. One of the advantages of this technique is that, with a little effort, a large amount of time can be frittered if the activity one chose to do until, say, the quarter-hour starting time, can be extended just a few minutes beyond this starting point. The student is then, by the same logic, justified in waiting until the next prominent time division. Depending on the individual and on the amount of time already spent in time 
symmetry fritters, the student can choose to wait for the next hour, half-hour, or quarter-hour. As good a fritter technique as this is, there is a problem in its use. Each time it is used in succession, the student feels less justified in invoking the time symmetry fritter. This is sometimes manifested by the setting of the starting time at progressively shorter prominent intervals: e.g., at 7:00, 8:00, 8:30, and then $8: 45$. In any event, at some point, this technique loses its efficacy. Fortunately, there is a larger-scale, more successful technique which can then be used.

\section{THE GREAT DIVIDE FRITTER}

At some point, say, in an evening to be devoted to work, it becomes too late to get serious work done (or finish the task, the scheduled amount, or what have you). At this point, the student feels perfectly free to give up for the rest of the night all pretense to studying. It is simply too late to get enough work done to make any work worthwhile. Some other activity is then chosen to occupy the remaining time, but without any need for a higher-good valuative justification. Thus, a particular student might not consider it worthwhile to start studying after 9:00 at night. The time-symmetry fritter brought the student up to $8: 45$, a biological-imperative fritter or a phone-call-for-acommiseration fritter might be sufficient to add enough time to set up a great divide fritter.

\section{SCHEDULING FRITTERS}

Students justify spending enormous amounts of time making up work schedules. These can be done for the day, evening, week, or whatever the relevant work session to be planned. Plans can be made not just for the coming work, but also for coming work breaks. Fritters of the future become bound into a longer series of work intentions and are in that way neutralized. Of course, scheduling may be resorted to whenever the actual progress of the work falls far enough off schedule to warrant the writing of a new one. Schedule-related fritters, then, 
become a consideration whenever something goes wrong or could go wrong with the schedule. Indeed, the more detailed the schedule, the greater the chance of derailment.

There are two salient forms of scheduling fritters. First, there are anticipated interruption fritters. If one knows in advance that at a certain point in the work period, studying will be interrupted by some other activity, there is set up a situation in which frittering the time until after the interruption is justified. This can be considered the application of a great divide fritter on a smaller scale. Second, there are disruption-of-sequence fritters. These occur whenever the student, for some reason, performs a task out of order from the planned sequence. If this involves successful completion of the different task, conditions are set up for an owe-it-to-yourself fritter as well as a new scheduling fritter. The disruption of sequence can also justify waiting for a new prominent starting point, like a new day, before actually working.

\section{DEADLINE CHANGE FRITTERS}

On occasion a teacher will change the date that some work is due either for the whole class or. by special arrangement, for single students. When this happens, the student feels free to use a postponed-deadline fritter. Since study time is reckoned backward from a deadline date rather than forward to new work opportunities, when the deadline is postponed, time is freed to avoid working. If, for example, a paper due Friday is postponed for one week on Wednesday, the student can wait for the following Wednesday before working again.

\section{Preparation-Related Fritters}

Preparation fritters involve all activities immediately attendant to preparing to study: getting books, paper, pens, cleaning the desk, and what have you. These are easily justified activities, preparatory as they are to work. These immediate preparations are easily escalated. Thus, a student decides that, in the interest 
of greater efficiency, he should clean his desk top (no matter what the actual nature of his work habits-tidy or abominable). Having done this, a crucial point is reached. He can now actually start to work. Instead, he says while-I'm-at-it and proceeds to clean out the whole desk, or rearrange all his books, or even move on to cleaning the whole room or apartment. This technique is especially interesting, developing as it does from the preparation fritter, in that it quickly ignores the originally work-related starting point. A good job is worth doing well, as long as it isn't the good job you have to do.

Preparation can be difficult (or made difficult), and work can be delayed. In the spread-resources or shuttle fritter the student does not bring, or chooses work for which he cannot bring, all the needed materials to one place for work. Travelling between work sites becomes necessary. What started as the path to work intersects with other paths (perhaps to other places).

\section{Creativity Fritters}

Once all the material preparations have been completed there are two other factors left to be prepared-the student and, say, the paper. Let us consider these in reverse order. Preparation of the paper itself will offer many opportunities for work avoidance.

(1) For the-first-step-is-the-hardest. This can mean working for a long time on an outline or, commonly, working hard at getting exactly the proper first sentence or first paragraph. The opening of a paper is felt in an important way to constrain the range of alternatives, stylistic and organizational, for the rest of the work. It becomes, therefore, of utmost importance that the opening be precisely correct-no matter how much time it takes.

(2) In addition, the student must be ready to work. Every creative endeavor, however, has an incubation period and every endeavor, creative or not, requires motivation. Both needs can require time, justified time. It is best to wait until you are bursting with ideas or are sufficiently motivated, even if the 
motivation is guilt due to unsuccessful previous application of fritter techniques. This is therefore the let-it-brew-for-a-while fritter (closely related to this is the I'll-lie-down-and-thinkabout-it fritter; the possible danger in this tactic is, of course, very clear; listing all things people are designed to do horizontally, studying is one of the lowest on the list).

(3) Related to these is the I'm-sure-there-is-something-else fritter. No matter how much advanced preparation there has already been, the conscientious student is justified in allowing some free time to think of something else which should be included (say, in a paper, or when considering how to psych out the teacher's exam questions). This is especially useful when. for example, a paper is on a topic requiring an interdisciplinary approach or a number of different viewpoints for elucidation. The "something else" can then be in an area only vaguely related to the original topic. This justification can thus successfully be used to allow additional time for readings and thinking more and more peripheral to the original topic-i.e., to the work itself. When the task is taking a test, students can spend a great deal of time trying to psych out the teacher. Information on prior exams and teachers' specialization or personal quirks may be important in deciding what significant knowledge is.

\section{Task-Involved Fritters}

Finally, the student, to remain in concept and in fact a student, must occasionally actually work. Once work is started, however, there are still some devices which can be used to slow it or end it quickly without endangering one's view of self as student.

(1) One important consideration, especially to someone who has been using scheduling fritters, is a reliable measure of how quickly the work is going. Time is thus justifiably spent computing pages, hours, words per minute, or what have you. This is the what's-myrate fritter. 
(2) Every work goal can be divided into subgoals whose individual accomplishments are significant since each contributes to the final completion. This is the principle behind the logical-stopping-point fritter. Small owe-it-to-yourself fritters are justified by the completion of the subgoals. As the time symmetry fritter has prominent dividing points for the time continuum, so the logicalstopping-point fritter divides up the work task itself. Thus, for example, one may set up subgoals such that one is justified in taking a break after completing only a single chapter in an assigned book. This technique, however, like the time symmetry fritter, is conducive to fractionalization. The subgoal can shift from finish the chapter to finish the topic of discussion or, more extremely, the page or the paragraph.

(3) Sometimes the student has more than one project to work on at once. The jack-of-all-trades fritter is a way of avoiding working too hard on any one subject by shifting from task to task before the work gets too taxing in any one of them.

(4) The hard-working student occasionally reaches a difficult place in his work. Work may slow down in the face of difficulty and require intense concentration. Overinvolvement, overconcern, and improper distance from the work may create problems. The student can then choose from a wide variety of more proper, and comfortable, distances from the work.

(5) As a result of using other fritter strategies, the working student may find the work cannot be done as desired in the remaining time before its deadline. It is possible to do an incredible-shrinking-work fritter. This allows a "settling process" to take place in which the wheat is separated from what becomes chaff.

\section{Recovery Fritters}

Sometimes the student does not complete the task when it is due. If he can get an open-ended extension, he is free to postpone additional work for a long time. This is the effect of the you-can't-pick-up-spilled-milk fritter.

\section{FRITTERS AND GUILT}

This presentation has been silent as to why fritters are 
successful in getting their work (avoiding work) done. It is clear how the time is frittered away, but it is not yet very clear how the student staves off guilt. Some suggestions of the mechanisms follow.

Many fritters deny that work performances are not being done as they should. A large number of fritters, especially task-related ones, disguise themselves as ways to get the task done. They either facilitate work (e.g., preparation), promise to improve it (e.g., related areas), or look like work (e.g., jack-of-all-trades). Biological necessity is sometimes seen as needed to get the task done, though occasionally this is a justification in its own right. Alternately, fritters can deny that there should be any pressure felt for not working. On one hand, the past shows no danger (prior capability, successful past work avoidance); on the other, there are no real consequences of not working (a form of what-the-hell sort. ... ).

Other fritters turn the fritterer's attention to other values above the successful study. These put the student role in larger perspective (alternate values) or put work in limits of "propriety" (appeals to fairness, "reasonable work" definitions).

Some fritters place special conditions on the way that work is done. Certain times to start (time symmetry), times to make progress (great-divide, anticipated-interruption), and times and places to stop (logical-stopping-point) are used to structure work sessions.

Finally, fritters can neutralize work pressure by subtle (or not so subtle) changes in how the definition of work is made. Is work "really" make work (one form of what-the-hell...), doing better than others (social-comparison), for posterity or your proctor (involved in pysch-out fritters), work you do or work due (postponed-deadline), a magnum opus or just some work (incredible-shrinking work)?

\section{CONCLUDING REMARKS}

Elements of the above presentation of fritter strategies lend themself readily to further research. Different fritters are used 
for different kinds of work. They are offerable as accounts to different others. Different others are needed to invoke particular fritters. Different fritters are used at different points in the phases of a work act. Different fritters are more subjectively available in different places, as, for example, the number of work cues varies by setting, requiring different fritter strategies. A student's cleaning the entire library before settling down to work would be rare. Some fritters are used without social support; others are not. Different materials are needed to use different fritters. Different fritters are used by students at different stages in their academic careers. Conditions which facilitate the adopting of different particular strategies must be elaborated. There is no evidence available yet on whether there are different subcultures of fritter or if these justifications are common currency among students in general. Because they are accounts to self which are only sometimes offered to others, students are often surprised when discussion reveals how widespread is their use.

There are features of the student role which facilitate the use of these strategies. Students are granted great liberty in the planning of their use of time. Student time is more often "individual time" than "social time." Time demands are stricter in high schools than in colleges. Required class time and daily evaluated assignments are less characteristic of the college years. The schools frequently cite the increased maturity of the students as the reason for the greater liberty permitted. However, time use in statuses occupied by even more mature adults are frequently more regulated by institutions. Perhaps most important, the student is in a transitional role. The schools and the population as a whole are not favorably disposed to lifetime students. It is an early stage in commitment to professional careers and a late stage in formal education for yet other careers. Widespread use of fritter techniques can ease the difficulties of early commitment for the former and aid the termination of formal education for the latter. 


\section{REFERENCES}

MATZA, D. (1964) Delinquency and Drift. New York: John Wiley.

SCOTT, M. and S. LYMAN (1970) "Accounts, deviance and social order," pp. $89-119$ in J. D. Douglas (ed.) Deviance and Respectability. New York: Basic Books.

--- (1968) "Accounts." Amer. Soc. Rev. 33, 1: 46-62.

\section{ANGRY ADOLESCENTS}

by RONALD GOLDMAN, Dean, School of Education, LaTrobe University, Melbourne, Australia

A first-hand account of a group of adolescents in a small CONTENTS British town near London-describing their delinquent and near-delinquent behavior and the struggle to create a genuine youth community. The author outlines the environment of these hostile young people, the poor provision for their leisure and further education, and their accumulative sense of inferiority... emphasizing the potential eventually released by an experimental youth club This volume will be welcomed by teachers, youth and social workers, and other professionals who work with young people in "affluent societies."

Dr. Goldman, a teacher and educational psychologist, has had constant contact with young people during his career -both as a teacher and a researcher. He has, in a voluntary capacity, run experimental youth centers... one of which is described in this book. Among his previous publications is Breakthrough: Autobiographical Account of the Education of Some Socially Disadvantaged Children.

$\$ 4.95$ / SBN 8039-0026-0 / 128 pp. / L.C. 71-82897 Introduction

Berrocfield in its Social Setting

How the Youth Club Began

The First $Y$ ear is Always the Norst

The Second YearWidening Horizons

The Third YearThe Crest of the Wave

How Unlike the Home Life of Our Dear Queen

The Litmus Paper of Society

Order from:

SAGE PUBLICATIONS / 275 S. Beverly Dr. / Beverly Hills, Calif. 90212 